\title{
Integration of scientific and technologically based photonics courses
}

\section{Moho Kamil Abd-Rahman}

Moho Kamil Abd-Rahman, "Integration of scientific and technologically based photonics courses," Proc. SPIE 4588, Seventh International Conference on Education and Training in Optics and Photonics, (28 May 2002); doi: $10.1117 / 12.468753$

SPIE Event: Education and Training in Optics and Photonics 2001, 2001, Singapore, Singapore 


\title{
Integration of Scientific and Technological-Based Photonics Courses
}

\author{
M. Kamil Abd-Rahman \\ Faculty of Applied Science, Universiti Teknologi Mara, 40450 Shah Alam, Malaysia \\ Email: mohdkamil.abdrahman@physics.org
}

\begin{abstract}
Among the main objectives of designing a photonics course based on the integration of Science and Technology is to produce job-ready graduates with sufficient fundamental knowledge and hands-on experience with optoelectronics and photonics devices and systems. The course is designed to present the fundamental concepts in photonics and these concepts are further enhanced with the engineering principles. Hands-on experiments on the basic components are essential in comprehending the principles and knowledge learned earlier. These leads to students who are competent of handling various sophisticated and sensitive photonics equipment and devices, furthermore they will acquired the essential fundamental knowledge and their applications of both the photonics devices plus equipment and the know-how on the telecommunication network systems and protocols.
\end{abstract}

Keywords - Photonics education, optical communications, fiber-optics education, fiber optics devices, optical amplifiers

\section{INTRODUCTION}

Optical telecommunication enables more information to be transmitted over greater distance than any other communications technology. Optical and photonics technology is expected to be as important to the 21 st century as electricity was to the 20 th century. There is an enormous demand for scientists, engineers, and technicians who can design, install, test, operate and maintain optoelectronic components and systems. In view for the necessity and demand for trained personnel in this area of global interest, colleges and universities throughout the world are introducing appropriate courses in optoelectronics and optical communications at undergraduate and postgraduate levels. Fiber-optics telecommunications has shown to be the most important application of photonics. Here we present the outline of a proposed course on photonics that integrate the fundamental scientific principles and the engineering principles with hands-on experimental experience and field training. The objective of the course is to produce job-ready graduates that possess essential knowledge on photonics plus an added value as competent trained personnel in both aspects of photonics devices and telecommunication network systems.

\section{PHOTONICS COURSE}

Such courses on photonics and related studies on optical telecommunications should generally include the principles, characteristics and applications of photonics devices, 
as for example the optical fibers, optical waveguides, semiconductor lasers, optical modulators, optical amplifiers (EDFA), optical switches, photo-detectors and receivers. There are a wide variety of optoelectronic components and photonic devices necessary to generate, modulate, guide, amplify, switch and detect light. Optical components are complex devices that form the backbone behind telecommunication networks. Receivers, transmitters, modulators, amplifiers and switches are examples of active components. Passive components operate on the light passing through the fiber and do not require power or electronics. Their function is to filter, divide or combine the light signals traveling through the optical fiber. Passive devices include couplers, isolators, and wavelength division multiplexers and demultiplexers. The emergence of advanced multimedia applications, world-wide regulatory changes, the introduction of new data services, and the increasing popularity of work-at-home applications, have all contributed to an unprecedented need for higher carrying capacity along fiber networks. Advances in dense wavelength division multiplexing (DWDM) technology have supported the increases in network transport capacity. An optical communications system with DWDM links comprises of semiconductor laser diode transmitter, optical multiplexer/demultiplexer, optical fiber, optical amplifiers/repeaters and photodiode receivers. The schematic of an optical telecommunication system described above is depicted in Fig.1.

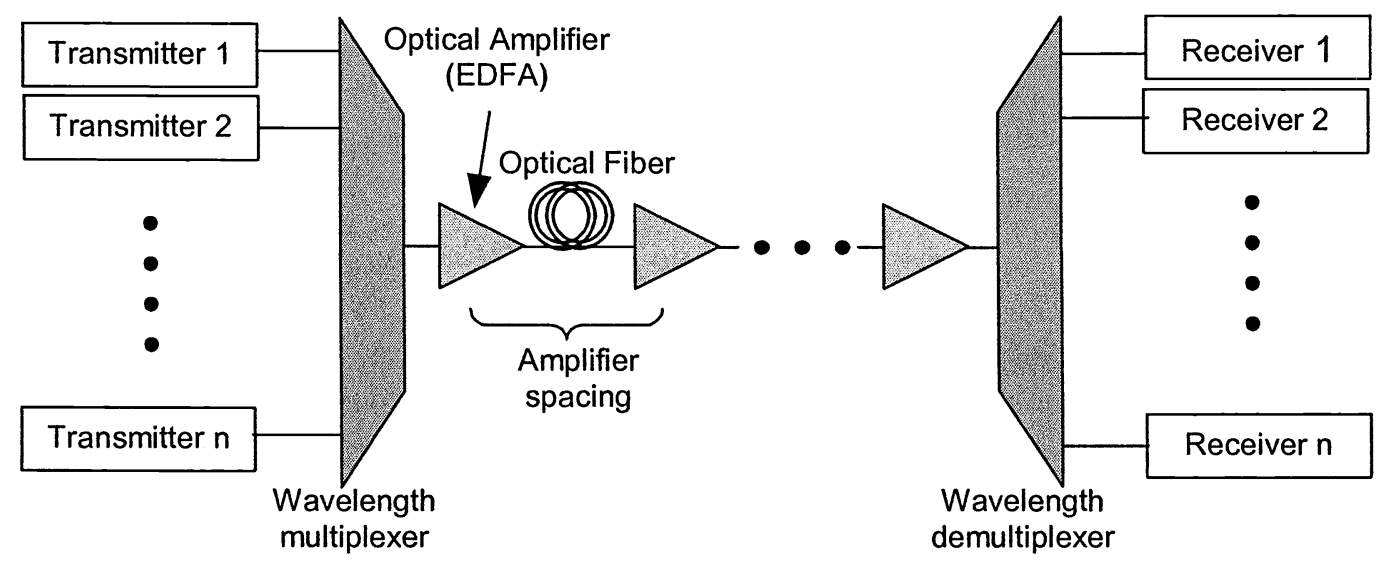

Fig. 1: A typical optical telecommunication system.

The course, which has been designed for intermediate and advanced level, aimed at undergraduates or postgraduates at Master's level. Furthermore, they are suitable for technical colleges and training institutes where students are undertaking technical training courses in photonics or optical communications technologies. The students should be able to consolidate their understanding and knowledge on photonics with experimental exercises and acquires practical experience of the design, analysis, and characteristics of photonics components and systems. This is to ensure those most important scientific and technical issues and phenomena are well addressed. The idea of implementing the course program on how the fundamental concept in photonics leads into technical design principles, which in turn forms part of the building block of a more complex network system is illustrate by the course content flow in Table 1. 
Table 1: Course content flow of the Photonics Course

\begin{tabular}{|c|c|c|c|c|c|}
\hline \multirow{3}{*}{ 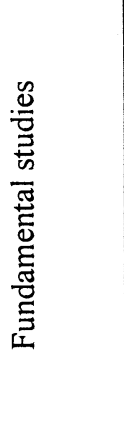 } & Physics & $\begin{array}{l}\text { Geometrical } \\
\text { optics }\end{array}$ & Physical Optics & Electromagnetism & $\begin{array}{l}\text { Quantum } \\
\text { mechanics }\end{array}$ \\
\hline & Mathematics & $\begin{array}{l}\text { Calculus, } \\
\text { Engineering } \\
\text { Mathematics } \\
\text { \& Statistics }\end{array}$ & $\begin{array}{l}\text { Differential } \\
\text { Equation }\end{array}$ & Matrix method & $\begin{array}{l}\text { Series \& } \\
\text { Boundary } \\
\text { problems }\end{array}$ \\
\hline & Elective $\square$ & $\begin{array}{l}\text { Digital } \\
\text { Electronics }\end{array}$ & $\begin{array}{l}\text { Communication } \\
\text { transmission } \\
\text { techniques }\end{array}$ & $\begin{array}{l}\text { Computer system } \\
\text { \& programming } \\
\text { language }\end{array}$ & $\begin{array}{l}\text { Material } \\
\text { properties \& } \\
\text { characterization }\end{array}$ \\
\hline \multirow{2}{*}{ 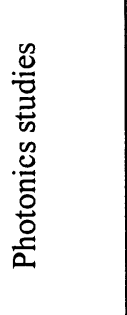 } & Fiber optics & $\begin{array}{l}\text { Lightwave } \\
\text { propagation }\end{array}$ & $\begin{array}{l}\text { Laser physics \& } \\
\text { applications }\end{array}$ & $\begin{array}{l}\text { Optoelectonics } \\
\text { properties in } \\
\text { material }\end{array}$ & $\begin{array}{l}\text { Modal boundary } \\
\text { condition }\end{array}$ \\
\hline & $\begin{array}{l}\text { Material } \\
\text { absorption, } \\
\text { dispersion \& } \\
\text { light scattering }\end{array}$ & $\begin{array}{l}\text { Energy } \\
\text { levels and } \\
\text { atomic rate } \\
\text { equations }\end{array}$ & $\begin{array}{l}\text { Maxwell } \\
\text { propagation } \\
\text { equations }\end{array}$ & $\begin{array}{l}\text { Optical } \\
\text { modulation \& } \\
\text { switching }\end{array}$ & $\begin{array}{l}\text { Nonlinearity in } \\
\text { optical materials }\end{array}$ \\
\hline 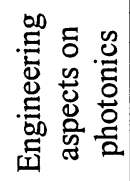 & $\begin{array}{l}\text { Optoelectronics } \\
\text { devices (active } \\
\text { and passive } \\
\text { devices) }\end{array}$ & $\begin{array}{l}\text { Optical } \\
\text { waveguides }\end{array}$ & $\begin{array}{l}\text { Practical laser } \\
\text { technology }\end{array}$ & $\begin{array}{l}\text { Optical design } \\
\text { and fabrications }\end{array}$ & $\begin{array}{l}\text { Fiber optics } \\
\text { tests and } \\
\text { measurements }\end{array}$ \\
\hline 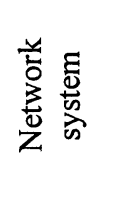 & $\begin{array}{l}\text { Topology, } \\
\text { routing, } \\
\text { addressing \& } \\
\text { internetworking }\end{array}$ & $\begin{array}{l}\text { Optics \& } \\
\text { electronics } \\
\text { for data } \\
\text { transmission }\end{array}$ & $\begin{array}{l}\text { Wavelength } \\
\text { division } \\
\text { multiplexed } \\
\text { systems }\end{array}$ & $\begin{array}{l}\text { Network } \\
\text { architecture \& } \\
\text { protocols }\end{array}$ & $\begin{array}{l}\text { Signal } \\
\text { processing, bit- } \\
\text { error-ratio \& } \\
\text { eye diagram } \\
\text { analysis }\end{array}$ \\
\hline
\end{tabular}

The basic building block in the course content comprises of the essential supportive subjects and these can be divided into several selected topics on physics, mathematics and some elective subjects, such as digital electronics, communication transmission techniques, computer system and programming language, and material properties and characterizations. Geometrical and physical optics, electromagnetism and quantum mechanics will be the focus on the study in physics, while advanced calculus and statistics with matrix, series and boundary-value problems will be emphasized in mathematics. These are the introductory part of the course content and they are extremely useful and important, in which they will be put to use in comprehending the concepts in photonics and their application in the engineering principles. As for example, the study on geometrical and physical optics would lead to the understanding of the lightwave propagation and modal boundary conditions, and these 
are further applied into the engineering principles of modal dispersion and cut-off wavelength of a dielectric waveguide as the basic photonics device [1].

The topics on photonics, which are listed in Table 1, address the principles and characteristics of fiber optics system. Lightwave propagation in cylindrical optical fiber and planar optical waveguides can be explained from the optical properties of dielectric materials by solving Maxwell equations. These topics are inter-related and supporting one another and illustrates a continuous flow in building up the understanding of the concept in photonics and applying it to the engineering principles. The subject integration links up to addressing the application of the principles into the design and fabrications of optoelectronics and photonics device. Fiber optics tests and measurements system guide and train students with the standard techniques of test and measurement via proper handling of equipment, devices and their related components in the fiber optics link. The fiber optics tests and measurements system is required for fiber optic devices and systems maintenance, and could provide the projection of designing future devices and systems [2].

The topic the network system forms a complete set of study on fiber optics telecommunication in which it covers all the essential elements of device applications in the network system for the photonics course. Signal processing, bit-error-ratio and eye diagram analysis provides the fundamental study on the data transmission characteristics. The study on network topology, routing, addressing and internetworking gives an overall understanding for the applications and limitations of optoelectronics and photonics devices in the network systems.

Photonics laboratory experiments provide specific experimental experience of the fiber optics telecommunication system and devices as well as broad exposure to many of the most important principles of photonics in general. The experimental exercises enable students to consolidate their understanding and knowledge of photonics as presented in the lectures and to acquire practical experience of the design, analysis, and characteristics of photonics components and systems. The design of photonics laboratory experiments includes the design of dedicated hardware, experimental procedures, exercises, and manuals. The experiment topics can be generally divided into six sections, namely transmitter lasers and LEDs, the optical waveguides, optical fiber telecommunication system, optical amplifiers (EDFA), photo detectors/receivers and optical network analysis.

Practical field training provides students with the real working environment and experiences the challenge of solving actual problems in the real world. These will indirectly call for exercising the knowledge to what ever that have been learned and taught in the lecture classes formally in the institute. The practical field training is most appropriately be schedule in the upper years of their studies. New experiences and problems acquired during the field works could be shared or be solved among peers or in college. Such training will eventually develop students to be professional with a broader prospective in understanding the overall system and program of study, and giving them the added-value of being job-ready graduates. The field training can be conducted at various telecommunication companies, research institutions and through inter-university-programs. 


\section{CONCLUSION}

Basic physical concepts in photonics lead into the engineering design principles, which in turn yield components and systems for the complex optical fiber telecommunication networks. In achieving the objectives of delivering competent students in this wide area of great interest, it is essential to take a fully integrated approach to consolidate the studies on photonics, engineering and network system as a whole and enhancing their understanding with modern technology-based photonics laboratory experimental packages. However, the constraint of the experimental packages is the cost, thus careful selection of the final packages must be affordable within higher education budgets.

\section{REFERENCE:}

1. Walter Johnstone, Brian Culshaw, Douglas Walsh, David Moodie, And Iain Mauchline, "Photonics Laboratory Experiments for ModernTechnology-Based Courses", Proc. of the IEEE, vol. 88, no. 1, pp. 41-54, 2000.

2. Dennis Derickson et-al, "Fiber Optics Test and Measurement", Prentice Hall PTR, New Jersey, 1998.I

3. “B.S. Photonics Curriculum", SUNY Inst. of Technol. Photonics Prog., 1997.

4. "Lecture syllabus - Photonics systems", Cambridge Univ., 2001. 